\title{
Utilization of Objective Structured Clinical Examination (OSCE) in Ensuring Clinical Competence of Nursing Students: A Case of FCMS
}

\author{
William Taala, Dania Waggas, Parisa H. Sta. Teresa \\ Fakeeh College for Medical Sciences, Jeddah, KSA \\ Email:wtaala@fcms.edu.sa,dswaggas@fcms.edu.sa,Phteresa@fakeeh.care
}

How to cite this paper: Taala, W., Waggas, D. and Teresa, P.H.Sta. (2019) Utilization of Objective Structured Clinical Examination (OSCE) in Ensuring Clinical Competence of Nursing Students: A Case of FCMS. Open Access Library Journal, 6: e5209. https://doi.org/10.4236/oalib.1105209

Received: January 28, 2019

Accepted: March 3, 2019

Published: March 6, 2019

Copyright $\odot 2019$ by author(s) and Open Access Library Inc.

This work is licensed under the Creative Commons Attribution International License (CC BY 4.0).

http://creativecommons.org/licenses/by/4.0/

\begin{abstract}
Fakeeh College for Medical Sciences nursing department is currently imposing the Objective Structured Clinical Examination (OSCE) as an academic system for its nursing students. This is to test the clinical skills and abilities in ensuring the competency and performance of future health providers. This is a type of clinical examination that uses hands on method of the real world situation of learning as an exposure aided by various medical cases. Among the tested subject, critical care emerged as the highest weighted average obtained by the students $(\mathrm{n}=22 ; \mathrm{x}=94.14)$ with an equivalent description of "excellent" while in contrast to fundamentals of nursing 2 which garnered (n $=66 ; \mathrm{x}=79.70$ ) with an equivalent description of "Good" as the lowest among the subjects. To reinforce the findings, this study made used of Focus Group Discussion (FGD) and Codification Technique to protect the identity of the respondents and its confidentiality as part of research ethics. The data revealed that a general observation from the narratives provided the conduct of OSCE is fair, accurate, and necessary that fits the nursing program of the institution except on the issue of time frame that can be resolved. The clinical issues such as confidentiality, examination and impact are so far in place and a revisit is necessary for improvement. Challenges involving conduct of the examination and quality of the examination must be given due consideration as pointed according to the need of time. This study concludes that OSCE is generally acceptable as an examination system in the nursing program of the institution.
\end{abstract}

\section{Subject Areas}

Nursing 


\section{Keywords}

OSCE, Nursing, Clinical Competency, Clinical Issues, Clinical Challenges

\section{Introduction}

Consumers of healthcare require competent health professionals on their health services for public health growing demands. According to the American Nurses Association (ANA) [1], the issue of health competency is an accountability of the health profession including: professional nurses, health organizations, accrediting and certification agencies, regulatory entities, employers, and other key stakeholders (Strong, 2018) [2]. It is true with nursing; then, it is also true to other health care professions, as part of the healthcare team. A clinical competency is one if not the main goal of a school of health sciences to instill and nurture in their students. It is the aim of each school to produce graduates who could work in their respective fields with the so-much efficiency and competency, things that are honed back in their college days. It is futile to allow incompetent students to graduate because of the harm they might cause to their patients. That is why, there are approaches devised by scholars and leaders in the health care to ensure that graduates of health sciences are well-equipped and ready to face the challenges of the professions they are endowed with. OSCE is one of these approaches. Moreover, this study analyzes the impact of the utilization of OSCE to the nursing students of FCMS. Further, this study will answer the questions: 1) What is the level of competency of students using the OSCE? 2) What are the areas that students need to improve as suggested by the OSCE result? 3) How does OSCE influence the students towards achieving a certain degree of clinical competence? 4) What are the setbacks of this approach as to the students' perception? 5) What are the students' suggestions that can be considered in the implementation of OSCE according to their context and without sacrificing the structure and objectives of OSCE?

\section{Review of Related Literature}

\subsection{OSCE Defined}

According to the Medical Council of Canada (2018) [3], an OSCE (Objective Structured Clinical Examination) form part of health sciences as a type of examination. This is to test the clinical skills and abilities in ensuring the competency and performance of the health provider. A type of clinical examination that uses hands on method of the real world situation of learning as an exposure. Accordingly, the contents of OSCE have scoring procedures that are standardized. There is a specific focus on an area of clinical competence in a given examination. The scoring tool will provide the overall picture of the performance of the examinees in areas of competency and under performance (Harden \& Gleeson, 1979) [4]. Harden (2009) [5] identified this as an approach in measur- 
ing the clinical performance in which the components of competencies are identified in structured way that is centered to the objectivity of the clinical examination.

\subsection{The Process and Stations of OSCE}

All OSCE candidate will undergo the same given problem and task to perform within a given time frame. The level of examination difficulty is the same regardless of a given venue or location of the examination using same marking and ranking scheme.

Using this approach, the student will be assessed in series of situations involving aspects of competencies. This examination arranges 20 stations where students will rotate since this is a hands on examination also known as practical examination. Each of the station will be given specific number of time/minutes before moving to another station of competency simultaneously. This type of examination is also known as "multi-station" examination and is highly encourage in clinical tests (Harden, 2009) [5].

The OSCE examination is provides real life examination in each station to solve, this will provide a complete assessment of clinical knowledge and skills on its application in meeting with patients/victims. OSCE provides a complete assessment of hands on techniques, communication skills, professional ethics, biomedical ethics and work attitudes for effective interaction with patients and other health professionals. OSCE is a test skill conducted on hands on performance given in a mock type situation (https://mcc.ca, 2018) [6].

\subsection{Rating in OSCE}

Typically, an OSCE, as stated earlier, consists of a series of independently scored stations, each of which involves a standardized patient who portrays a clinical scenario (Hodges, n.d.) [7]. Performance is scored in each station by an examiner who ticks off items on a binary checklist while the candidate interacts with the standardized patient, or in some cases by the standardized patient following the conclusion of the interaction. IN addition, the examiner or standardized patient may complete one of more global ratings regarding more general dimensions of performance following the encounter.

\subsection{The Challenges in OSCE}

The challenge is that in the vast majority of OSCEs, checklists account for the bulk of marks awarded to candidates. In these, the use of global ratings in the final mark reported for the candidates was never suggested in several papers presented relevant to the use of checklist in OSCE. (Hodges, Regehr, McNaughton, Tiberius, \& Hanson, 1999) [8]. Recently, while studying the validity checklists and global ratings, Hodges, and colleagues discovered that residents obtained lower scores than did medical students on checklists despite their higher global ratings (Hodges, et al. 1998) [7]. A growing literature on the development of expertise suggests a possible explanation for this surprising finding. For example, 
Dreyfus and Dreyfus (1986) [9] identified that the problem solving involves levels of expertise in stages. Commonly professionals pass through five stages in the developmental process: novice, advanced beginner, competence, proficiency, and expertise.

There are two characterizations on this between a novice and an expert, a novice stage gives emphasis on the collection of large amounts of data-in no particular order and with little regard for situational factors-which are then used to synthesize a problem solution. While an expert gathers much more on centered or refined information, relies on many type of data, including situational variables, applies methodology and validation techniques.

Using a similar model, Schmidt, Norman, and Boshuizen (1990) [10] posited that the development of competence involves four stages: the development of elaborated causal networks, the compilation of elaborated networks into abridged networks, the emergence of illness scripts, and the storage of patient encounters as instance scripts. Health professionals encapsulate large bodies of knowledge which will allow them to interpret large amounts of information quickly and effectively with little formal effort. These encapsulated modules are unpacked only with a concerted effort, which suggests that it would be difficult for the expert to perform a diagnostic procedure with the formal thoroughness that a novice might ("Hodges", n.d.).

These theories were products of clinical investigations. For example Leaper (1973) [11] studied the behaviors of 28 surgical clinicians ranging from intern to consultant, all members of the professorial surgical unit in the University of Leeds. The study recorded what questions the clinicians asked and in what order in clinical interviews of patients with abdominal pain. In 137 observed encounters, Leaper found that interview lengths varied from ten to 30 questions. Junior clinicians carried out a stereotypical interview, asking questions in the same order quite irrespective of whether they were relevant to the particular case. Senior clinicians had a much more flexible, more relevant questions that yielded more information.

\subsection{Pervasiveness of OSCE}

OSCE has been used in over 67 countries particularly in Europe. In Western countries like the UK, OSCE is designed to assess one's ability to competently apply professional skills and knowledge ("About the OSCE," n.d.). It is set at the level of expected of nurses and midwives as they enter the profession. Thru this method nurses and midwives are expected to apply their knowledge and skills to the patients. The examination is not just about testing what they remember in in training schools but its application to real life situation guided by empirical evidence and practice (https://www.brookes.ac.uk, 2018) [12].

\subsection{Conceptual Framework}

The discussion of this paper shall be centered on three main findings such as 1) 
Clinical Competence of nurses (nursing students) using OSCE. 2) Clinical Issues towards the conduct of OSCE and its impact. 3) Clinical Challenges derives from the experience of OSCE.

Figure 1 shows the centrality of OSCE in producing clinical competence among graduates. However, in its implementation there are setbacks that need to be addressed. Also, there are suggestions from the students to consider making the implementation more contextual.

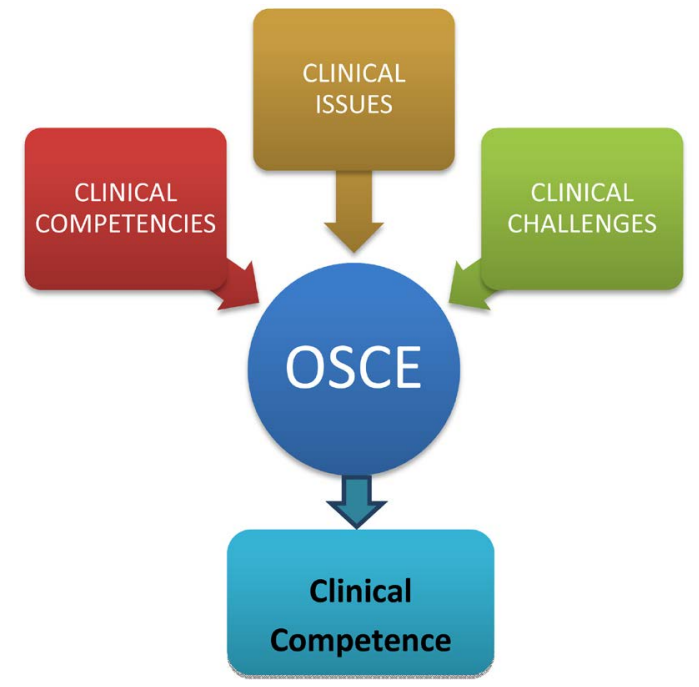

Figure 1. Conceptual framework.

\section{Methodology}

This is a single case study that focuses on an in-depth analysis of the use of OSCE in FCMS. In this research, OSCE results were summarized and analyzed. To reinforce the discussion and come up with a theme, in-depth interviews, triangulated with observations and Focused Group Discussion (FGD) was utilized. There were at least 5 participants asked to join the qualitative part of this research and would undergo interview and FGD. Using the editing style of data/narrative analysis, themes were extracted from the narratives coming from the interview, observation, and FGD. Then, discussion surrounding each theme was done. The research is conducted in FCMS. The five participants were coded following codification technique as part of the research protocol of the college in providing confidentiality to the identity of the respondents. The following respondents were coded as; Code Alpha, Code Bravo, Code Charlie, Code Delta and Code Echo.

\section{Discussion and Presentation}

\subsection{On the Grades of the OSCE}

The following nursing major subjects were taken into consideration of this study as these were the latest subjects where OSCE examinations were conducted (Table 1). 
Table 1. Weighted average grades of the OSCE students.

(a)

\begin{tabular}{ccccc}
\hline No. & Subject & N & Weighted Average & DI \\
\hline 1 & Nursing Fundamentals 2 & 66 & 79.70 & Good \\
2 & Psychiatric Nursing\& Mental Health Nursing & 19 & 91.26 & Excellent \\
3 & Women's Health & 19 & 80.45 & Very Good \\
4 & Critical Care & 22 & 94.14 & Excellent \\
5 & Child Health Nursing & 19 & 89.14 & Very Good \\
6 & Adult Health & 28 & 89.10 & Very Good \\
\hline
\end{tabular}

(b)

\begin{tabular}{|c|c|c|}
\hline \multicolumn{2}{|c|}{ Grades } & \multirow{2}{*}{$\begin{array}{c}\text { Percentage } \\
95-100\end{array}$} \\
\hline Excellent & $A+$ & \\
\hline Arabic: مناز & A & $90-94$ \\
\hline Very good & $\mathrm{B}+$ & $85-89$ \\
\hline Arabic: جيد جداً & B & $80-84$ \\
\hline Good & $\mathrm{C}+$ & $75-79$ \\
\hline Arabic: جيد & C & $70-74$ \\
\hline Acceptable & $\mathrm{D}+$ & $65-69$ \\
\hline Arabic: مقبول & $\mathrm{D}$ & $60-64$ \\
\hline $\begin{array}{c}\text { Failure } \\
\text { Arabic: راسب }\end{array}$ & F & $0-59$ \\
\hline
\end{tabular}

Gleaned from the above table are the results of the OSCE grades of the students which comprise $30 \%$ of the total grades of the subject. Of the six subjects with OSCE examination, Critical Care garnered the highest weighted average grade $(\mathrm{n}=22 ; \mathrm{x}=94.14)$ with an equivalent description of "excellent". This was followed by psychiatric and mental health nursing $(\mathrm{n}=19 ; \mathrm{x}=91.26)$ also with an equivalent description of "excellent". However, notably among the subjects which garnered the lowest grades is the fundamentals of nursing ( $n=66 ; x=$ 79.70) with an equivalent description of "good". This means that this subjects needs more effort from the instructors as this is an introductory subjects that introduces nursing's skills of the students.

\subsection{On What the Students Can Say about Their Experiences on OSCE}

Three main themes emerged from the responses of the participants pertaining to 1) Clinical Competence of nurses (nursing students) using OSCE 2) Clinical Issues towards the conduct of OSCE and its impact 3) Clinical Challenges derives from the experience of OSCE.

On the Clinical Competence using OSCE

Clinical competence of using OSCE can best explain from the responses pro- 
vided by the participants in the FGD involving (a) Test Quality, (b) Time Frame and (c) Result Accuracy. This segment provides clarity on the personal experiences encountered by the nursing students of FCMS on the conduct of OSCE as a system measuring their academic performance as preparation to the actual work experience.

\begin{tabular}{|c|c|}
\hline CODEFICATION & RESPONSES ON TEST QUALITY \\
\hline Code Alpha & $\begin{array}{l}\text { I liked the OSCE as a method of examination because it's a non-traditional } \\
\text { approach in testing the mental and practical skills of the students in clinical } \\
\text { situations. }\end{array}$ \\
\hline Code Bravo & $\begin{array}{l}\text { The instrument/method of examination is recognized in other universities } \\
\text { and I take this positively. }\end{array}$ \\
\hline Code Charlie & $\begin{array}{l}\text { I find it unusual because all my life what I know about examination is } \\
\text { written. I preferred that the examination is written rather than practical. }\end{array}$ \\
\hline Code Delta & $\begin{array}{l}\text { The activity is very practical and I liked the way it tested my mental and } \\
\text { practical skills in dealing the situation. }\end{array}$ \\
\hline Code Echo & $\begin{array}{l}\text { This is a good method of examining our mental and practical skills because it } \\
\text { assess our responses towards a real world situation. }\end{array}$ \\
\hline
\end{tabular}

OSCE is a system of evaluation that is evidence based practice in health science. This is a test of mental and practical skills of nursing students applied in FCMS. It is also known among them that this is being practice as well in other countries in the medical field. Though a few revealed that this is something new to them but generally it is being welcome as a system of examination in the college.

\begin{tabular}{cl}
\hline CODEFICATION & \multicolumn{1}{c}{ RESPONSES ON TIME FRAME } \\
\hline Code Alpha & $\begin{array}{l}\text { I think time pressure in the conduct of OSCE is just in a normal phase that } \\
\text { will test our mental and practical skills. }\end{array}$ \\
Code Bravo & $\begin{array}{l}\text { Its normal to have time pressure after all we are in the medical world, the } \\
\text { faster we move the better. }\end{array}$ \\
Code Charlie & $\begin{array}{l}\text { There are stations in the conduct of OSCE I find it shorter in time due to its } \\
\text { level of difficulties, I hope they will o something about this. } \\
\text { Code Delta }\end{array}$ \\
Code Echo & $\begin{array}{l}\text { This kind of method is power and speed test, the speed is a primary factor } \\
\text { ever since to me }\end{array}$ \\
& $\begin{array}{l}\text { The issue of time allotment is not an issue at all, I find in fair enough on my } \\
\text { part. }\end{array}$
\end{tabular}

It is true that time frame is an element in OSCE because it's necessary, a time is being allotted in every work station for you to solve not at a faster rate but in accordance to the time provided wisely. This examination is known as power and speed tests as a description for an OSCE measuring system. Scoring system is use in this examination to measure the overall performance of the nursing student in handling emergency cases according to respective working stations.

\begin{tabular}{cl}
\hline CODEFICATION & \multicolumn{1}{c}{ RESPONSES RESULT ACCURACY } \\
\hline Code Alpha & $\begin{array}{l}\text { I could only speak on my part, I do well in this method of examination. It fits } \\
\text { my system. }\end{array}$ \\
\hline
\end{tabular}




\section{Continued}

\begin{tabular}{cl}
\hline Code Bravo & $\begin{array}{l}\text { So far so good, I pass all examination under this system. } \\
\text { Code Charlie }\end{array}$ \\
Code Delta & $\begin{array}{l}\text { My scores are not too good using this kind of examination I preferred the } \\
\text { traditional way. }\end{array}$ \\
Code Echo & $\begin{array}{l}\text { This examination treated all students fairly considering we are undergoing } \\
\text { the same process. }\end{array}$ \\
\hline
\end{tabular}

The data and scoring accuracy which form part of the grading system in evaluating the mental and practical skills of nursing students. Both the data and scoring system were carefully reviewed by the professor/administering officer. It is a unique way of measuring the academic performance that is acceptable even in other nursing schools across the globe.

\section{On the Clinical Issues towards the conduct of OSCE and its impact}

Clinical issues towards the conduct of OSCE and its impact of using OSCE can best explain from the responses provided by the participants in the FGD involving (a) confidentiality issues (b) examination issues and (c) impact. This segment provides clarity on the personal experiences encountered by the nursing students of FCMS on the conduct of OSCE as a system measuring their academic performance as preparation to the actual work experience.

\begin{tabular}{|c|c|}
\hline CODEFICATION & RESPONSES ON CONFIDENTIALITY ISSUES \\
\hline Code Alpha & $\begin{array}{l}\text { The situations in the OSCE will definitely test our skills both mental and } \\
\text { practical because these are clinical situations that are why I value the data } \\
\text { being provided. }\end{array}$ \\
\hline Code Bravo & $\begin{array}{l}\text { This kind of methodology is necessary the professor explains it clearly the } \\
\text { confidentiality of the data. }\end{array}$ \\
\hline Code Charlie & $\begin{array}{l}\text { I admit that the system of OSCE is no joke because of its level of difficulty, } \\
\text { there is a tendency that I talked about the subject matter outside the class. }\end{array}$ \\
\hline Code Delta & $\begin{array}{l}\text { At first I am curious about some cases that were presented, the people behind } \\
\text { the scenario but eventually I learned to live by it. }\end{array}$ \\
\hline Code Echo & $\begin{array}{l}\text { There are cases presented that are confidential, it's good that names were } \\
\text { coded in our examination. }\end{array}$ \\
\hline
\end{tabular}

In medical field confidentiality is an important issue even in the conduct of OSCE it involves medical data pertaining to medical cases assigned in various working stations to be solved during the conduct of the examination. It is therefore necessary that confidentiality must be observed by the students which form part of both the medical and research ethics of the institution.

\begin{tabular}{cl}
\hline CODEFICATION & \multicolumn{1}{c}{ RESPONSES ON EXAMINATION ISSUES } \\
\hline Code Alpha & $\begin{array}{l}\text { There is no way for you to cheat in this examination because we are assigned } \\
\text { according to respective stations and move simultaneously. }\end{array}$ \\
Code Bravo & $\begin{array}{l}\text { Cheating is really an issue but not in OSCE because of the nature of the ex- } \\
\text { amination. }\end{array}$ \\
\hline
\end{tabular}


Continued

$\begin{array}{ll}\text { Code Charlie } & \begin{array}{l}\text { There are instances actually that I wish to take a glance however working } \\ \text { stations were arranged in distance. }\end{array} \\ \text { Code Delta } & \begin{array}{l}\text { I tried to do language sign in one of the examinations, however the professor } \\ \text { has full concentration on us. }\end{array} \\ \text { Code Echo } & \begin{array}{l}\text { Idon't have issues on the examination, unless of course if the professor will } \\ \text { leak the data ahead of time. }\end{array}\end{array}$

An application of codification technique is suggested similar to this study for the protection of people involve in medical cases. Cheating is also an issue but not in this case so far, this is due to the distance of each working stations. To avoid such scenario, the department must emphasize in its handbook the possible sanction for violating confidentiality and the manifestation of cheating.

\begin{tabular}{|c|c|}
\hline CODEFICATION & RESPONSES IMPACT NOW AND BEYOND \\
\hline Code Alpha & OSCE is about practice and this is close to the real situation \\
\hline Code Bravo & $\begin{array}{l}\text { This system will really help us in the real world of work, I am confident I can } \\
\text { do my job in the hospital }\end{array}$ \\
\hline Code Charlie & $\begin{array}{l}\text { I don't see yet the importance of this method as of now, may be it will in the } \\
\text { future }\end{array}$ \\
\hline Code Delta & $\begin{array}{l}\text { I agree that this will help us in the future in administering emergency cases in } \\
\text { the hospital }\end{array}$ \\
\hline Code Echo & No doubt, this is very important for future application in the medical world \\
\hline
\end{tabular}

The data also revealed that the nursing students value the importance of OSCE as a training system and as a tool for future world of work, they know that they are expose in various medical and emergency cases that is testing both mental and practical skills. The narratives provide positive feedback on the conduct of OSCE as a model system for academic evaluation.

On the Clinical Challenges derives from the experience of OSCE

Clinical Challenges derives from the experience of OSCE can best explain from the responses provided by the participants in the FGD involving (a) challenges in confidentiality, (b) challenges on the conduct of the examination and (c) challenges on the quality of the examination. This segment provides clarity on the personal experiences encountered by the nursing students of FCMS on the conduct of OSCE as a system measuring their academic performance as preparation to the actual work experience. This segment provides clarity on the personal experiences encountered by the nursing students of FCMS on the conduct of OSCE as a system measuring their academic performance as preparation to the actual work experience.

\begin{tabular}{cc}
\hline CODEFICATION & RESPONSES ON CHALLENGES IN CONFIDENTIALITY \\
\hline Code Alpha & $\begin{array}{l}\text { Medical cases presented in the OSCE must be given due respect by the } \\
\text { administering officer and the students }\end{array}$ \\
Code Bravo & $\begin{array}{l}\text { The administering officerl professor must make it clear to the class the } \\
\text { importance of confidentiality of the data and the value of respect }\end{array}$ \\
\hline
\end{tabular}




\section{Continued}

\begin{tabular}{|c|c|}
\hline Code Charlie & $\begin{array}{l}\text { This is just to suggest to lessen the presentation of medical cases instead } \\
\text { make use of hypothetical cases }\end{array}$ \\
\hline Code Delta & Gadgets and other devices must be out of reach during the examination \\
\hline Code Echo & $\begin{array}{l}\text { A clear cut policy must be introduce on possible penalty for those violating } \\
\text { the confidentiality of the examination and medical cases presented }\end{array}$ \\
\hline
\end{tabular}

This segment pertains to various challenges of OSCE in FCMS, to preserve its credibility as to confidentiality the department must provide a clear orientation about the working system. The institution may review the application of medical cases and hypothetical cases as suggested by the participants.

\begin{tabular}{|c|c|}
\hline CODEFICATION & RESPONSES ON THE CONDUCT OF THE EXAMINATION \\
\hline Code Alpha & $\begin{array}{l}\text { The number of students taking the OSCE simultaneously should be reviewed } \\
\text { if this will still fit in the future. }\end{array}$ \\
\hline Code Bravo & $\begin{array}{l}\text { The sequencing of stations during the examination should be reviewed for } \\
\text { fair treatment. }\end{array}$ \\
\hline Code Charlie & The time allotment must be review in this kind of examination. \\
\hline Code Delta & $\begin{array}{l}\text { The conduct of OSCE must be classified into easy, average and difficult and } \\
\text { must be administered in separate schedule to coincide with the time frame. }\end{array}$ \\
\hline Code Echo & $\begin{array}{l}\text { This depends upon the situation, the professor should be strict on the } \\
\text { conduct of the examination. }\end{array}$ \\
\hline
\end{tabular}

The data also suggested to emphasize the policy and procedures on the conduct of OSCE and continues review or revisit of it for improvement and tuning it according to the phase of time and the learning environment. All other factors such as time, scoring, sequencing, etc. as suggested must be reviewed by a team for a better working system of OSCE in FCMS.

\begin{tabular}{|c|c|}
\hline CODEFICATION & $\begin{array}{l}\text { RESPONSES ON THE CHALLENEGS ON THE QUALITY OF } \\
\text { EXAMINATION }\end{array}$ \\
\hline Code Alpha & Cases presented in the OSCE are relevant, so far I don't have issues on this. \\
\hline Code Bravo & $\begin{array}{l}\text { I recommend this kind of examination at this age of time and I think useful } \\
\text { even in the future. }\end{array}$ \\
\hline Code Charlie & $\begin{array}{l}\text { Questions must be proof read, sometimes I have difficulties in reading long } \\
\text { sentences/ paragraphs. }\end{array}$ \\
\hline Code Delta & Hope there will be more cases about our areal localize cases. \\
\hline Code Echo & $\begin{array}{l}\text { To maintain the quality of the examination, may be a standardize OSCE can be } \\
\text { considered by the management. }\end{array}$ \\
\hline
\end{tabular}

The quality of this kind of system in measuring the academic performance is challenge by the kind of cases being provided, the credibility of the administering officer or the professor. As they say, it is not about getting the correct answer but asking the correct question at first. A correct question can lead to correct answer but a wrong question can never lead to correct answer. There are only two affecting factors that will challenge the quality of OSCE 1) the substance of 
the questions and 2) administering the examination that is fair and honest.

\section{Conclusion}

General observation from the narratives provided the conduct of OSCE is fair, accurate, and necessary that fits the nursing program of the institution. The clinical competence of using OSCE is generally acceptable except on the issue of time frame that can just be resolved. Time pressure is really a factor between a fast learner and the slow learner; it will always be a factor between power test and speed test. However, OSCE can never be a free time frame; there must be a time frame to protect the confidentiality of the examination and the agility of young professionals in responding to medical emergencies. As to the Clinical issues towards the conduct of OSCE and its impact of using OSCE as to confidentiality issues, examination issues and impact are so far in place and a revisit is necessary for improvement of the system. The institution is rightfully fitted in this system as revealed by literature; as it is widely practice across the globe and supported by the narratives of the participants that concur to the importance of this system as a training tool. As to the Clinical Challenges derived from the experience of OSCE involving challenges in confidentiality, challenges on the conduct of the examination and challenges on the quality of the examination must be given due consideration for the improvement of OSCE. It is suggested that OSCE can be reviewed by a team of experts from the nursing department and other allied sciences as to its accuracy and dept. This study concludes that OSCE is generally acceptable as an examination system in the nursing program of the institution that will definitely prepare young professionals in the real world of work.

\section{Acknowledgements}

The authors would like to thank the anonymous referees for your valuable connects and suggestions.

\section{Conflicts of Interest}

The authors declare no conflicts of interest regarding the publication of this paper.

\section{References}

[1] The American Nurse | Contact Us (n.d.). http://www.theamericannurse.org/contact-us/

[2] Strong, M. (2018) Maintaining Clinical Competency Is Your Responsibility: Learn How to Maintain and Enhance Your Competency. American Nurse Today, 11, 46-47.

[3] Medical Council of Canada (2018). https://mcc.ca/

[4] Harden, R.M. and Gleeson, F.A. (1979) Assessment of Clinical Competence Using an Objective Structured Clinical Examination (OSCE). ASME Medical Education Booklet No. 8. https://doi.org/10.1111/j.1365-2923.1979.tb00918..x 
[5] Harden, R.M. (2009) What Is an OSCE? Medical Teacher, 10, 19-22. https://doi.org/10.3109/01421598809019321

[6] MCCEE (n.d.). https://mcc.ca/examinations/mccee/

[7] Hodges, B. (2003) OSCE! Variations on a Theme by Harden. Medical Education, 37, 1134-1140. https://doi.org/10.1111/j.1365-2923.2003.01717.x

[8] Hodges, B., Regehr, G., NcNaughton, N., Tiberius, R. and Hanson, M. (1999) OSCE Checklists Do Not Capture Increasing Levels of Expertise. Academic Medicine, 14, 1129-1134. https://doi.org/10.1097/00001888-199910000-00017

[9] Dreyfus, H.L. and Dreyfus, S.E. (1986) Mind over Machine. Free Press, New York.

[10] Schmidt, H.G., Norman, G.R. and Boshuizen, E. (1990) Cognitive Perspective on Medical Expertise Theory and Implications. Academic Medicine, 65, 611-621. https://doi.org/10.1097/00001888-199010000-00001

[11] Leaper, D.J., Gill, P.W., Stanniland, J.R., Horrocks, J.C. and de Dombal, F.T. (1973) Clinical Diagnostic Process: An Analysis. BMJ, 3, 569-574. https://doi.org/10.1136/bmj.3.5880.569

[12] Oxford Brookes University (n.d.). https://www.brookes.ac.uk/ 